\title{
ERRATUM
}

\section{Erratum to: Do Property Rights Presuppose Scarcity?}

\section{David Faraci}

Published online: 20 November 2014

(C) Springer Science+Business Media Dordrecht 2014

\section{Erratum to: J Bus Ethics \\ DOI 10.1007/s10551-013-1866-0}

The Acknowledgment section inadvertently omitted from the original publication of this article has been included in this erratum.

Acknowledgments The bulk of this paper was written during my summer as a fellow at the Nanotechnology and Society Research Group at Northeastern University in 2011. Funding for this fellowship came from the National Science Foundation (Grant No. SES0609078). I am particularly grateful to Ronald Sandler, Co-Principal
Investigator for the NSRG, for granting me the opportunity to work alongside him and others as a fellow, and for his input on the paper. Thanks also to my fellow fellows: John Basl, Matt Kopec, Noah Levin, Patrick Smith and Valentina Urbanek; to the organizers and audience members of the 2012 annual conference of the Humanities and Technology Association; to my friend and colleague, Peter Jaworski; and to three anonymous reviewers at the Journal of Business Ethics. I would especially like to thank one of these reviewers, whose extremely detailed feedback helped clarify many aspects of my argument.

The online version of the original article can be found under doi:10.1007/s10551-013-1866-0.

D. Faraci $(\bowtie)$

UNC Chapel Hill, 207-D Caldwell Hall, Chapel Hill, NC 27599,

USA

e-mail: faraci@email.unc.edu 